\title{
Global Production Estimation of Rare Earth Elements and Their Environmental Impacts on Soils
}

\author{
Georgios Charalampides, Konstantinos I. Vatalis \\ Department of Environmental Engineering and Antipollution Control, Technological Educational Institute of \\ Western Macedonia (TEI), Kila Kozani, Greece \\ Email: chara@teiwm.gr
}

Received 18 September 2015; accepted 17 October 2015; published 20 October 2015

Copyright (C) 2015 by authors and Scientific Research Publishing Inc.

This work is licensed under the Creative Commons Attribution International License (CC BY). http://creativecommons.org/licenses/by/4.0/

(c) (i) Open Access

\begin{abstract}
Due to high demand and limited availability of rare earth elements (REEs), Europe is unable to meet its industrial needs, especially High Tech needs, today for the manufacturing sector. Therefore, the EU has included them in the group of 14 critical minerals. China currently controls completely the mining activity, the enrichment technologies and metallurgy, and end-metal products of rare earths, resulting both Europe and the U.S.A. in full industrial dependency. The exploitation and wide use of REEs in fertilizers have led to accumulation of these elements in soils, resulting in an agriculture field pollution, which affects directly the soil microfauna with a toxic potential effect.
\end{abstract}

\section{Keywords}

Rees, Production, Reserves, Environment, Fertilizers

\section{Introduction}

Cerium and neodymium, as major elements and praseodymium, samarium, europium, dysprosium, gadolinium, terbium, holmium, erbium, thulium, ytterbium and lutetium as subordinate amounts (including even lanthanum and often yttrium) comprise the REEs, which are also considered as critical elements due to their high tech industrial applications. Commonly, REE-bearing minerals are found scattered in a variety of forms, mostly as accessory minerals in igneous and metamorphic rocks, such as granites, gneisses and pegmatites [1]. The abundance of Ce is almost the same as environmentally much more studied elements, such as $\mathrm{Cu}$ and $\mathrm{Zn}$; the most scarce lanthanides, Lu and Tm are actually more abundant in the Earth's crust than Cd and Se. No other group

How to cite this paper: Charalampides, G. and Vatalis, K.I. (2015) Global Production Estimation of Rare Earth Elements and Their Environmental Impacts on Soils. Journal of Geoscience and Environment Protection, 3, 66-73.

http://dx.doi.org/10.4236/gep.2015.38007 
of elements in the periodic system displays such a great similarity as the REEs. They all usually form trivalent cations, though the divalent or the tetravalent oxidation state is known for most of them in chemical compounds. The effective ionic radius of the trivalent ions decreases gradually from $\mathrm{La}^{3+}(1.031 \AA)$ to $\mathrm{Lu}^{3+}(0.861$ A) [2].

The REEs are found, usually several together, in a variety of accessory minerals, such as phosphates, carbonates, fluorides and silicates. They rarely form more continuous ore bodies.

REEs do not occur as native elemental metals in nature, only as part of the host mineral's chemistry. For this reason, the recovery of Rare Earth Metals (REMs) must be accomplished through complex processing methods to chemically break down the minerals containing the REEs.

Despite the abundance of more than 200 known REE-bearing minerals, only three of them are considered to be the principal REE mineral ores most feasible for the extraction of REMs: bastnäsite, xenotime, and monazite [2].

About 17 REMs are usually found together, mostly in bestnäsite with iron in Bayan Obo (Inner Mongolia), monazite and xenotime ores with radioactive thorium (Mountain View, California and Kerala, India), and iron-adsorption clays [3] [4]. More than $95 \%$ of the rare earths occur in betstnäsite, monazite and xenotime [5]. Betstnäsite contains about 70\% - 75\% rare earth oxides (REOs), monazite $65 \%-70 \%$ and xenotime $61 \%$ - 67\% [6]. Betstnäsite ores [(Ce, $\left.\left.\mathrm{La}, \mathrm{Nd}) \mathrm{CO}_{3} \mathrm{~F}\right)\right]$ are fluorocarbonates of cerium, lanthanum, neodymium ant other REMs. Betstnäsite is the least problematic source of REOs, as it hardly contains any radioactive thorium [6] [7].

Rare earth elements (REEs) have previously been used as geochemical tracers in groundwater flow systems owing to the commonly reported similarities between their input-normalized REE patterns and those of the aquifer rocks/sediments through which they flow and react [8]-[11].

Rare earth elements (REEs) have been used in fertilizers in the agriculture of China for about 20 years. They have been shown to be beneficial elements for plants. For example, they have improved the yield and quality for several kinds of crops. Some studies have focused on the effects of REEs on metabolic nutrients, photosynthesis and stress resistance of plants. Other studies have shown that the environmental behaviours of REEs in soil are dominated by their low solubility. Fluorides, carbonates, phosphates and hydroxides may form neutral complexes containing REEs with a low solubility [12].

China has the largest reserves of REEs in the world (80\%) and is a major producer of REEs for the world market. Since 1990, REE fertilizer has been widely used in more than 20 Chinese provinces [13].

The environmental behavior of REEs in soil is dominated by their low solubility (Shuzhen Zhang and Xiao-quan, 2001). Fluorides, carbonates, phosphates and hydroxides may form complexes with neutral REEs with low solubility, resulting in low dissolved concentrations in the aqueous phase of ecosystems. In solution, REEs may be complexed with inorganic ligands (e.g. carbonate, sulfate), organic ligands (e.g. humic and fulvic acids) and, at a high $\mathrm{pH}$, with hydroxyl ions.

Rare earth elements (REEs) are not particularly rare in terms of abundance, but for many years remained rarely separated from each other owing to their similar chemical characteristics [14]. Although REEs (which are also known as the lanthanide series in the periodic table of elements) are widely distributed geographically, they are chiefly mined, concentrated, and separated in China.

Talens Peiro and Villalba Mendez [15] focused essentially on the chemical beneficiation of REEs for each type of mineral ore: bestnäsite, monazite and xenotime. Their work was an attempt to estimate the material and energy requirements for the production of REM based on the theoretical chemical reactions and thermodynamics. It was indicated that material and energy balances should be of use in life cycle analysis, resource accounting, and other industrial ecology tools used to quantify the environmental consequences of meeting REMs demand for new technology products.

As concerning the REEs occurrences in Greece, significant reserves of these elements are found in alluvial deposits in the coastal and groundwater environment of Strymona gulf between Strymona River and Kavala region, Northern Greece. Specific ore deposits research estimates ore reserves of 485 million $t$ with an average content of 1.7\% rare earths. According to Eliopoulos et al. [16], REEs are observed in Greece in three types of mineralizations: 1) in laterite/bauxite ore bodies, Central Greece; 2) in black sands derived from plutonic rocks, in the area of Strymonikos Gulf, Northern Greece and 3) in granites and granitic pegmatites of Samothrace island, Northeastern Aegean Sea. However, detailed and systematic investigations show that these bauxites and la- 
teritic bauxites of Central Greece contain representative concentrations, ranging overall from 3275 - $6378 \mathrm{~g} / \mathrm{t}$ REE. It must also be stressed that there is still an emerging interest for the red mud from the aluminum metallurgy [17].

This paper reviews the current literature on world reserves and production of REEs and studies on using them as fertilizers and their environmental impact.

\section{World Reserves and Production of Rare Earth Oxides}

The global Rare Earth Reserves by country are given in Figure 1. The reserve is defined by the USGS [18] as "the part of the reserve base which could be economically extracted or produced at the time of determination". On the contrary, the reserve base not only comprises the resources that are currently economic (= reserves) but also marginally economic reserves, and some of those that are currently sub-economic.

It is to be expected that both the reserve base and the reserve will increase in the years ahead because the steep increases in REOs prices lead to the exploration of new deposits. For example, the Chinese Ministry of Commerce announced in October 2010 that a new large rare earth deposit was found in Central China [19]. Figure 2 displays the top countries in Rare Earth mine production worldwide for the period 2010-2013 [20].

On the other hand the trend of world production of RRE was increasing in recent decades, as shown in Figure 3 [18] [20] as compared the figures of the period 1990 to 2013, where the main contribution comes from China,

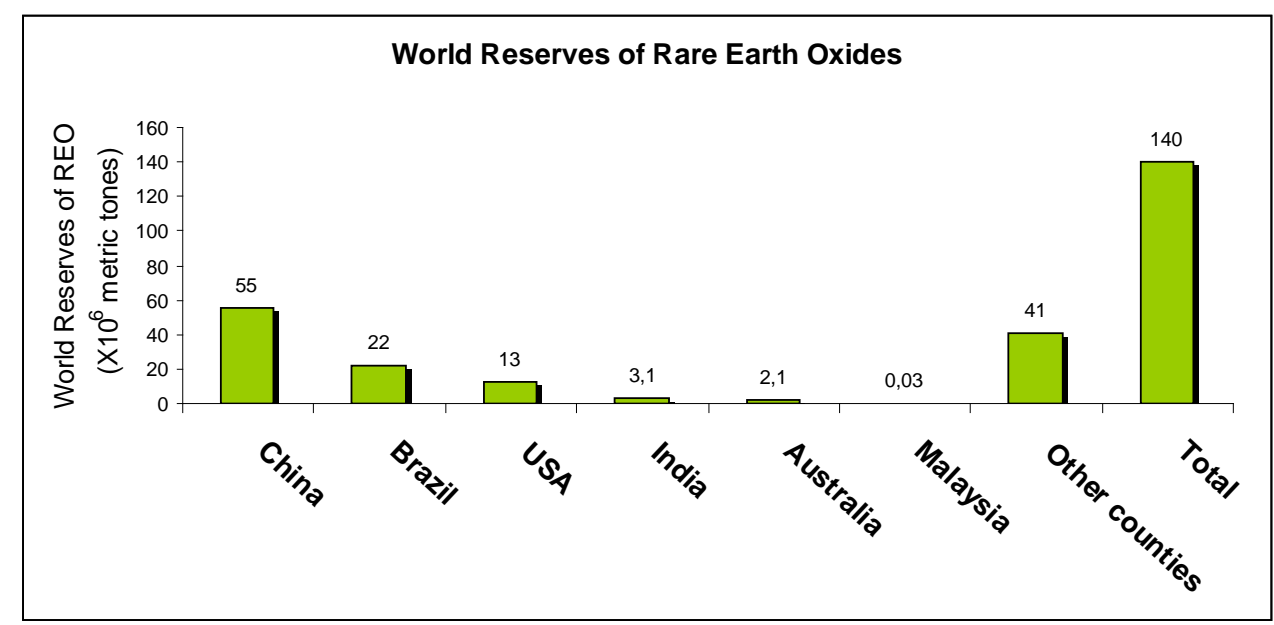

Figure 1. The possible global rare earth reserves, by country, as they are estimated by [20].

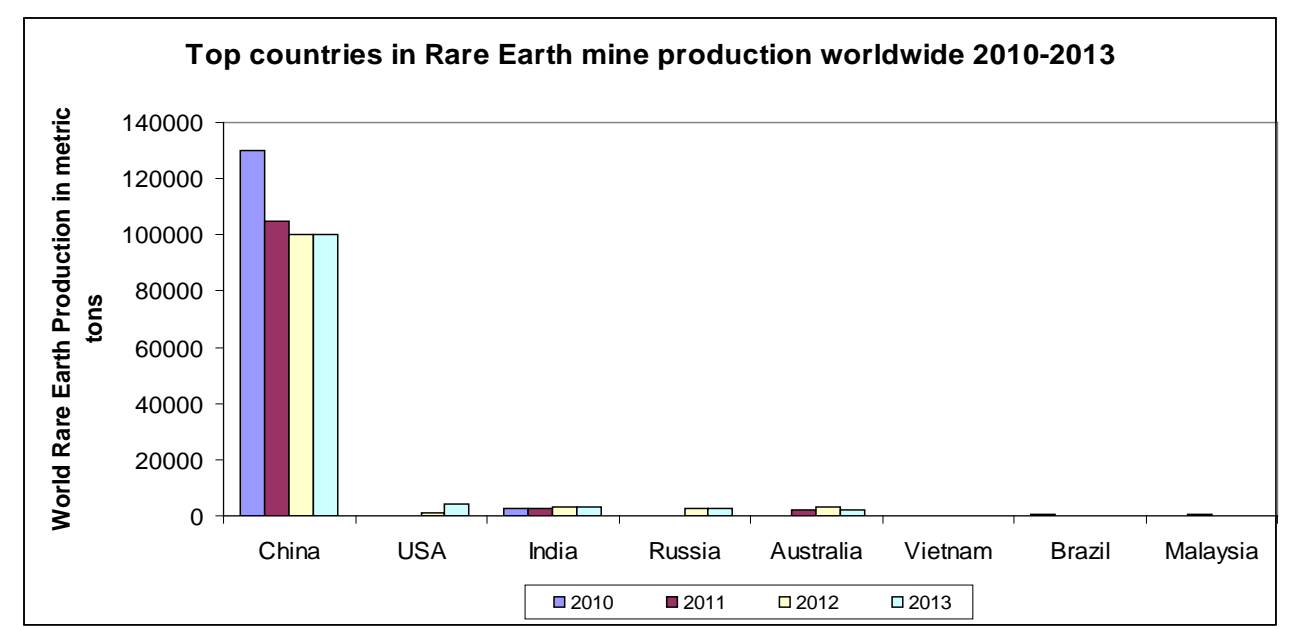

Figure 2. Top countries in rare earth mine production worldwide during 2010-2013 (after [20] \& http://www.statista.com/statistics/268011/top-countries-in-rare-earth-mine-production [22]). 


\section{World Mine Production of Rare Earth Oxides}

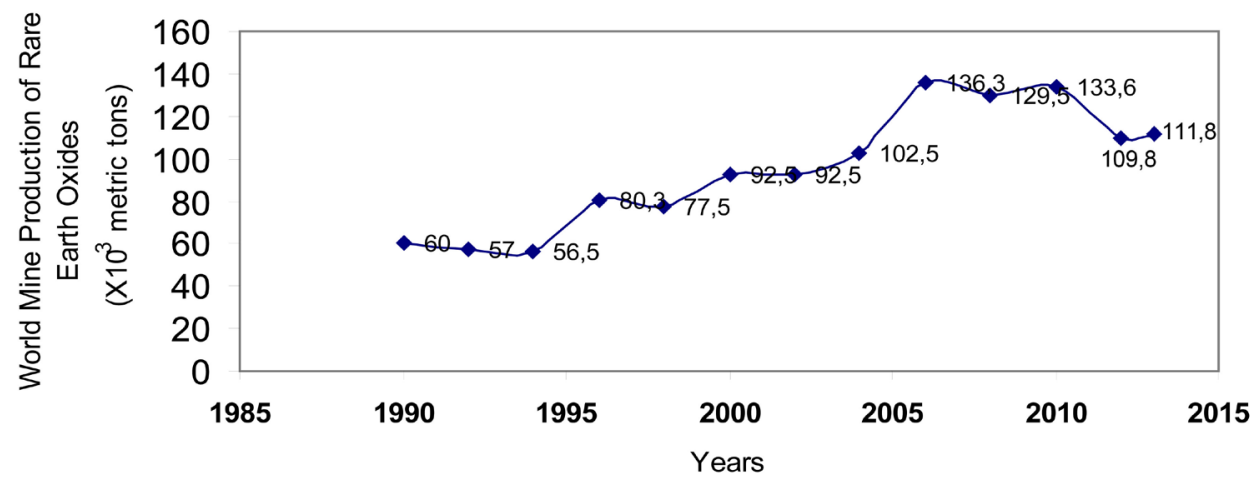

Figure 3. World mine production of REO, as it was estimated by US geological survey (modified after [18] and [20]).

which holds about $90 \%$ of world production, reaching 2013 to 111,800 t. The figure points out the steady increase in the rare earth production due mainly to continuous increase of the Chinese market share, particularly since 2002, when the American mine was closed due to environmental problems and low competitiveness because of low Chinese prices [21]. Though the fact that China produces more than $95 \%$ of the global production, their share of the reserves is much lower at 38\%. Large deposits are also found in the USA, Australia and states of the former Soviet Union.

China continued efforts to restrict the supply of REOs and consolidate its rare earth industry. China's rare earth production and export quotas for 2013 were 93,800 tons and 31,000 tons, respectively.

In 2010, about 54,000 tons of rare earths were produced from bestnäsite in iron ores, 12,000 tons from bestnäsite, 11,000 from monazite and xenotime and 37,000 from iron-adsorption clays, which totaled almost 114,000 tones [15]. There is a first group of REMs produced in annual amounts greater than 10,000 tons (cerium, lanthanum, neodymium and yttrium), a second group that includes praseodymium and dysprosium, both of which are produced in thousands of tons. Metals produced in amounts lower than 10,000 tons can be regarded as by-products of lanthanum, cerium, neodymium and yttrium.

Generally, there are about 34 countries with rare earth deposits widely distributed in the world. In this sense they are not very rare. It is believed that in future more rare earth deposits will be discovered.

The physical and chemical beneficiation of bestnäsite is different from that of monazite and xenotime, as bestnäsite is a carbonate-fluorite mineral while monazite and xenotime are both phosphate minerals. The separation of rare earth elements poses many difficulties due to the great similarity of their chemical properties. Bestnäsite is separated from monazite due to the difference of their specific gravities using a shaking table.

\section{The Environmental Impact of REEs as Fertilizers}

During the past two decades, geochemistry of REEs has been widely used in the studies of groundwater systems and showed that REE abundances and their characteristics (Ce and Eu anomalies, fractionation of light and heavy REEs etc.) in groundwater systems were mainly controlled by the rocks through which they flowed over, $\mathrm{pH}$, redox conditions, solution chemistry, organic and/or inorganic complexation, colloidal and particulate matter transport [23]. However, using REEs in the future it will provide additional information about the water-rock interactions in deep seated environment and for building the foundation of water source discrimination.

Recently, the environmental pollution of rare earth elements (REE) has increased dramatically as a result of wide application of REEs in agricultural production as microelement fertilizers as well as in industry. Therefore, the biogeochemical cycling of REEs and their ecological and environmental effects are greatly concerned by many researchers. Rock weathering is an important REE source for an ecological system and a key process of global biogeochemical cycling of REE [24]. REE enrichment characteristics and mechanism analysis reveal that the released REE from weathering of carbonate rocks (mainly limestone), sillicalite and shale are mainly stored 
in profiles.

In addition to their use in industry, REEs are more widely applied to cropland as microelement fertilizers due to their abilities to increase yields and improve qualities of crops. As a result, more and more REEs are moving into the ecosystems. They accumulate in soils, bioaccumulate in crops, and enter the food chain, causing a problem of REE environmental pollution special to China. In recent years, REE environmental effects have become of great concern [25]. Some work should be done to and a method should be developed that can reliably estimate bioavailability of REEs to plants and thereby evaluate the potential health risk of REEs in soils and predict their impact on the ecosystem.

Recent great improvements in more routine analytical technique, the use of REEs as fertilisers, at least in East Asian agriculture, and the importance of these elements as indicators in both pedological and physiological processes and reactions have contributed to an increased interest in these previously less considered elements in environmental sciences. It is well known that the different fractions of soils metals vary considerably in their chemical reactivity and bioavailability [26].

Several interactions between REEs and biological systems are known. Many studies in Chinese agricultural science have suggested that low concentrations of REEs may promote growth and productivity of several crops. Application of these elements, either to the seed or to the crop biomass is nowadays widely practised in Chinese agriculture, thus in a considerable part of the earth's cultivated soils. The physiological and ecophysiological mechanisms underlying their reactions have recently been given much attention.

Mixtures of REEs in fertilisers are nowadays widely used in Chinese agriculture to improve crop nutrition and have been in common use for about 20 years [27]. In most cases, however, La, several lanthanides, and probably $\mathrm{Y}$ are contained in the mixtures, making it difficult to conclude whether any single element is of particular importance or whether the effects are less element-specific, which seems most likely. The capacity of rare earth uptake by the roots might be limited, mainly due to the self-protection mechanisms of the plants against adverse effects of rare earths [28].

Approximately $80 \%$ of the world's resources of rare earths are found in China which is a major producer of them for the world market [29]. Considerable work has shown that the application of rare earths with suitable dosages can improve crop growth and production, as well as resistance to poor growing conditions.

The use of REEs in various industries, especially their wide use in agriculture, has gradually been observed as a potential environmental problem in China [30]. Most of the REEs applied as seed dressing or spray on growing crops will finally reach the soil. But the amounts applied annually are certainly small compared to the total amounts present in the soil. Even if all REEs would end up and remain in the soil, thousands of years are needed to double the natural total soil pool at the recommended rates of application. It has to be considered, however, that REEs supplied as fertilisers are much more soluble and reactive than the average soil pool and therefore of more immediate environmental interest.

The results of several studies [28] [30] showed that the accumulation of REEs in soil was significant in the study area and its concentration was strongly correlated with the distance from the pollution source.

Gillet and Ponge [31] have indicated that soil fauna is very sensitive to the changes in the soil environment. The soil fauna community responds to soil degradation and soil heavy metals pollution, such as $\mathrm{Cd}, \mathrm{Cu}, \mathrm{Pb}$ and $\mathrm{Hg}$, in many ways. Thus, soil fauna can be an indicator of soil degradation and soil pollution, and is often used to evaluate soil quality.

Heavy metal pollution of soil can lead the soil fauna community to change, but the response of different soil fauna to contamination is different. Almost all the deposits of REE contain the radioactive element thorium, and therefore environmental cost should be related to market competitive force.

\section{Discussion}

Due to high demand and limited availability of REEs, Europe is unable to meet today its industrial needs for the manufacturing sector. Therefore the EU has included them in the group of 14 critical minerals. Namely, China currently controls completely the mining activity (almost 95\% of world production) and thereafter the production, the enrichment technologies and metallurgy and end-metal products of rare earths, resulting for both Europe and the U.S.A. in full industrial dependency, reaching almost to $100 \%$. This is happening at a time when the demand and needs tend globally constantly growing at an annual rate of $8 \%-11 \%$. There are large differences in market prices of rare earth oxides. Also, the prices depend on the degree of purity determined by the 
specifications in the applications. The price ranges from $11 \$ / \mathrm{kg} \mathrm{La}_{2} \mathrm{O}_{3}$ to $1600 \$ / \mathrm{kg} \mathrm{Eu}_{2} \mathrm{O}_{3}$ (www.lynascorp.com [32]). However, it is of importance to emphasize that illegal trading practices are often used in China to circumvent direct control of important secondary raw material flows, including recycled REEs. Preliminary statistics of June 2014 show illegal smuggling hidden among 67 REEs recycling projects across the country. MIIT urged the government to regulate REE recycling [33].

While recovering the world economy from financial crisis and the boom of rare earth market, it seems to be very interesting and profitable to invest to rare earth industry. According to Chegwidden and Kingsnorth [34] and Watanabe [35], there are about 200 projects on rare earth exploration, under preparation and exploitation. Among so many projects, about 25 of them are promising to be the competitors of future multi-supply.

China government's decision to subsidize REE producers pursuing technological upgrades, shows the commitment of the country to address energy efficiency and environmental issue and to promote value added products [36].

The most promising producers out of China which could get into production recently should be MolyCorp, Lynas, Simelt of Estonia, Great Western Group, and three Japanese joint ventures in Vietnam, India and Kazakhstan. The total production capacity out of China after 2015 should be more than 170,000 tons [37].

The EC report from on the Implementation of the Raw Materials Initiative' of June 24, 2013 [38] confirmed that by 2020 actions would include: setting up innovative pilot projects, including demonstration plants on exploration, mining and processing; finding substitutes for raw materials in short supply; creating a network of research centers on sustainable raw materials management; using EU standardized instruments for surveying resources; creating a 3D geological map; modeling raw material trends; undertaking complete lifecycle assessment of EU raw materials needs.

\section{Conclusions}

Almost 50,000 tons of rare earths are needed per year out of China at present time. With a rate of $15 \%$ demand increase, then in 2015, the total demand out of China should be at least 80,000 tons on the basis of the world economy continuous increase. The products of exploitation could be rare earth concentrate and compounds like oxides, metals and alloys, depending on target consumer and the rare earth contents in the deposits.

The distribution of metals in the aerial parts of plants is the result of both the fixation and the transfer mechanisms. The complexation of organic ligands in the xylem vessels plays an important role, and elements with strong complexation capacities (strong motilities) are preferentially transported to the top. The REEs concentrations, as well as total nitrogen, total potassium, and $\mathrm{pH}$, had some effect on the soil macrofauna community. A small amount of REEs can promote soil macrofauna diversity, but a large amount of REEs can reduce the soil macrofauna diversity.

To fully understand the effects of REEs in agricultural application, environment and human health, it is suggested that future research in several areas is needed, which will shed new light on the effects of REEs on agriculture, environment and human health. First, the dynamic changes and fates of REEs used in fertilizers should be thoroughly investigated. Second, the indirect effects of REEs on human health and ecosystems through their use in agriculture should be explored. Third, it is necessary to make an assessment of REEs as hazards in their use in agriculture and to develop standards for soil quality.

\section{References}

[1] Greenwood, N.N. and Earnshaw, A. (1984) Chemistry of the Elements. Pergamon Press, Oxford.

[2] Tyler, G. (2004) Ionic Charge, Radius, and Potential Control Root/Soil Concentration Ratios of Fifty Cationic Elements in the Organic Horizon of a Beech (Fagus sylvatica) Forest Podzol. Science of the Total Environment, 329, 231-239. http://dx.doi.org/10.1016/j.scitotenv.2004.03.004

[3] Naumov, A.V. (2008) Review of the World Market of Rare-Earth Metals. Russian Journal of Non-Ferrous Metals, 49, 24.

[4] U.S. Geological Survey (USGS) (2011) Rare Earth Elements-End Use and Recyclability, Scientific Investigations Report 2011-5094, U.S. Department of the Interior.

[5] Gupta, C.K. and Krishnamurthy, N. (1992) Metallurgy of Rare Earths. International Materials Review, 37, 197.

[6] Gupta, C.K. and Krishnamurthy, N. (2005) Extractive Metallurgy of Rare Earths. CRC Press, Boka Radon. 
[7] Hambel, C.A., Ed. (1971) Rare Metals Handbook. 2nd Edition, Robert E. Krieger Publishing Co. Inc., Malabar, 715.

[8] Banner, J.L., Wasserburg, G.J., Dobson, P.F., Carpenter, A.B. and Moore, C.H. (1989) Isotopic and Trace Element Constraints on the Origin and Evolution of Saline Groundwaters from Central Missouri. Geochimica et Cosmochimica Acta, 53, 383-389. http://dx.doi.org/10.1016/0016-7037(89)90390-6

[9] Smedley, P.L. (1991) The Geochemistry of Rare Earth Elements in Groundwater from the Carnmenellis Area, Southwest England. Geochimica et Cosmochimica Acta, 55, 2767-2779. http://dx.doi.org/10.1016/0016-7037(91)90443-9

[10] Johannesson, K.H., Cortés, S.A., Ramos, L.J.A., Ramírez, G.A. and Durazo, J. (2000) “Rock-Like” versus “Seawater-Like” REE Signatures of Groundwaters. Geological Society of America. Abstracts with Programs, 32, A-188.

[11] J Janssen, R.P.T. and Verweij, W. (2003) Geochemistry of Some Rare Earth Elements in Groundwater, Vierlingsbeek, The Netherlands. Water Research, 37, 1320-1350. http://dx.doi.org/10.1016/S0043-1354(02)00492-X

[12] Zhang, S.Z. and Shan, X.Q. (2001) Speciation of Rare Earth Elements in Soil and Accumulation by Wheat with Rare Earth Fertilizer Application. Environmental Pollution, 112, 395-405.

[13] Yu, Z. and Chen, M., Eds. (1995) Rare Earth Elements and Their Applications. Metallurgical Industry Press, Beijing, 286-294.

[14] Cindy, H. (2010) China’s Rare Earth Elements Industry-What Can the West Learn? Institute for Analysis of Global Security, Washington DC, $42 \mathrm{p}$.

[15] Laura, T.P. and Gara, V.M. (2013) Material and Energy Requirement for Rare Earth Production. JOM, 65, $1327-1340$.

[16] Demetrios, E., George, E., Ioannis, T. and Christos, P. (2014) The Potential of Rare Earth Elements in Greece. Proceedings of the 1st European Rare Earth Resources Conference, Milos, 4-7 September 2014, 308-316.

[17] Arvanitidis, N. and Papavasileiou, K. (2011) Mineral Wealth. Institute of Geology and Mineral Exploration of Greece, Athens.

[18] USGS (2010) Mineral Commodity Summaries. US Geological Survey, Reston, VA.

[19] MOFCOM (2010) The Ministry of Commerce of the People’s Republic of China: Large Rare Earths Deposit Found in Central China.

[20] USGS (2014) Mineral Commodity Summaries. US Geological Survey, Reston, VA, 129-130.

[21] The Greens/EFA Group in the European Parliament, Final Report for Darmstadt (2011) Study on Rare Earths and Their Recycling. www.oeko.de

[22] http://www.statista.com/statistics/268011/top-countries-in-rare-earth-mine-production/.

[23] Sun, L.H., Gui, H.R. and Chen, S. (2011) Rare Earth Element Geochemistry of Groundwaters from Coal Bearing Aquifer in Renlou Coal Mine, Northern Anhui Province, China. Journal of Rare Earths, 29, 185.

[24] Song, Z.L., Liu, C.Q., Han, G.L. and Wang, Z.L. (2006) Enrichment and Release of Rare Earth Elements during Weathering of Sedimentary Rocks in Wujiang Catchments, Southwest China. Journal of Rare Earths, 24, 491-496.

[25] Cao, X.D., Wang, X.R. and Zhao, G.W. (2000) Assessment of the Bioavailability of Rare Earth Elements in Soils by Chemical Fractionation and Multiple Regression Analysis. Chemosphere, 40, 23-28.

[26] Davies, B.E. (1992) Inter-Relationships between Soil Properties and the Uptake of Cd, Cu, Pb and Zn from Contaminated Soils by Radish (Raphanus sativus L.). Water, Air, \& Soil Pollution, 63, 331-342. http://dx.doi.org/10.1007/BF00475500

[27] Pang, X., Li, D.C. and Peng, A. (2002) Application of Rare-Earth Elements in the Agriculture of China and Its Environmental Behavior in Soil. Environmental Science and Pollution Research, 9, 143-148.

[28] Diatloff, E., Smith, F.W. and Asher, C.J. (1976) Rare Earth Elements and Plant Growth: I. Effects of Lanthanum and Cerium on Root Elongation of Corn and Mungbean. Journal of Plant Nutrition, 18, 1963-1976. http://dx.doi.org/10.1080/01904169509365037

[29] Brown, P.H., Rathjen, A.H., Graham, R.D. and Tribe, D.E. (1990) Rare Earth Elements in Biological Systems. In: Gschneidner Jr., K.A. and Eyring, L., Eds., Handbook on the Physics and Chemistry of Rare Earths, Volume 13, Elsevier, Amsterdam, 423-452.

[30] Hu, X., Ding, Z.H., Chen, Y.J., Wang, X.R. and Dai, L.M. (2002) Bioaccumulation of Lanthanum and Cerium and Their Effects on the Growth of Wheat (Triticum aestivum L.) Seedlings. Chemosphere, 48, 621-629. http://dx.doi.org/10.1016/S0045-6535(02)00109-1

[31] Gillet, S. and Ponge, J.-F. (2006) Are Acid-Tolerant Collembola Able to Colonise Metal-Polluted Soil. Applied Soil Ecology, 26, 219-231.

[32] www.lynascorp.com.

[33] Torrisi, A. (2014) China’s Ministry of Industry and Information Technology Calls for Regulations on Rare Earths Recycling. Industrial Minerals Magazine, 13 June 2014. 
[34] Chegwidden, J. and Kingsnorth, D.J. (2010) Rare Earths: Facing the Uncertainties of Supply. Proceedings of the Sixth International Rare Earths Conference, Hong Kong, 9-11 November 2010.

[35] Watanabe, Y. (2010) Japan's Search for Alternative Rare Earths Supply. Proceedings of the Sixth International Rare Earths Conference, Hong Kong, 9-11 November 2010.

[36] Torrisi, A. (2014) China Government to Subsidise Environmental and Efficiency Upgrades of Rare Earths Companies. Industrial Minerals Magazine, July 10, 2014.

[37] Chen, Z.H. (2011) Global Rare Earth Resources and Scenarios of Future Rare Earth Industry. Journal of Rare Earths, 29, 1-6.

[38] Nicoletopoulos, V. (2014) European Policies on Critical Raw Materials, including REE. Proceedings of the 1st European Rare Earth Resources Conference, Milos, 4-7 September 2014. 